\title{
The Relationship of Dissociation Proneness to Secondary Trauma, Burnout, and Compassion Satisfaction in Mobile Crisis Workers
}

\author{
Keith A. Plouffe ${ }^{1}$ \\ ${ }^{1}$ School of Psychology, Walden University, Minneapolis, MN, USA \\ Correspondence: Keith A. Plouffe, Walden University, Minneapolis, MN, USA.
}

Received: March 23, 2015

Accepted: April 8, 2015

Available online: April 29, 2015

doi:10.11114/ijsss.v3i3.738

URL: http://dx.doi.org/10.11114/ijsss.v3i3.738

\begin{abstract}
This study examined the relationship between general dissociation experiences (DES) and dissociation absorption experiences (DESAB) to secondary traumatic stress (STS), burnout (BO), and compassion satisfaction (CS). Mobile crisis workers in Maine $(\mathrm{N}=30)$ anonymously completed the Dissociative Experiences Scale II and the Professional Quality of Life Scale; biographical data was masked. Results indicated high resiliency in this sample as $80 \%$ of scores reflected CS, while $24 \%$ of scores reflected STS and $7 \%$ reflected BO. Analysis produced moderate, statistically significant correlations between STS and DES $(r=.31)$; STS and DESAB $(r=.32)$; BO and DES $(r=.44)$; and BO and DESAB $(r=.43)$. CS and DES/DESAB did not yield a significant correlation. This suggests a previously unreported relationship between dissociation vulnerability and the experience of STS and BO. Findings warrant further study of STS as a manifestation of a primary trauma disorder and not a distinct category. Results can inform mental health provider training and burnout prevention efforts.
\end{abstract}

Keywords: secondary traumatic stress, vicarious trauma, burnout, compassion satisfaction, dissociation

\section{Introduction}

Professions at risk of secondary traumatic stress include individuals working in emergency services, law enforcement, healthcare, and mental health (Versola-Russo, 2005). Secondary traumatic stress hypothesizes that secondary exposure to the primary trauma experiences of others will produce in the helper symptoms similar to the individuals they assist. Given the scope of helping professions that have routine, caring exposure to another's trauma experience, the need to understand secondary traumatic stress is evident. However, an important gap remains in the literature in that the study of secondary traumatic stress has not addressed similarities or differences between secondary traumatic stress and trauma disorders, chiefly post-traumatic stress disorder (PTSD), in order to differentiate them. It is likely that secondary traumatic stress is really PTSD experienced by workers whose exposure to the traumatic events of others triggers the worker's own reexperiencing of his or her past trauma. Findings from the secondary traumatic stress literature, prevalence issues, and the concept of disorder suggest that secondary traumatic stress is a manifestation of an underlying, primary PTSD. The present study hypothesizes that secondary traumatic stress shares the key symptom of dissociation with PTSD and that dissociation likely plays a role in burnout.

\subsection{Secondary Traumatic Stress}

Secondary traumatic stress is often synonymous with concepts of vicarious trauma and compassion fatigue. These concepts share similar basic constructs with differences based on source of distress and their focus on different aspects of the distressing agent. Compassion fatigue and secondary traumatic stress refer to the manifestation of PTSD symptoms from exposure to someone else's trauma experience (e.g., verbal reports during assessment, therapy); compassion fatigue is the destigmatized term of secondary traumatic stress (Jenkins \& Baird, 2002). Vicarious trauma differs from secondary traumatic stress and compassion fatigue in that vicarious trauma focuses on cognitive shifts instead of symptoms per se, is more similar to burnout then traumatic stress, targets persons who work with childhood sexual abuse, and is the product of accumulative exposure, whereas secondary traumatic stress and compassion fatigue can theoretically occur in response to hearing a single client's story (Jenkins \& Baird, 2002; Kadambi \& Ennis, 2004). Secondary traumatic stress, compassion fatigue, and vicarious trauma therefore are similar in that each describes the reaction of helpers to the trauma of their clients with secondary traumatic stress and compassion fatigue targeting trauma symptoms and vicarious trauma targeting the cognitive impact on the helper. 
In a critical review of primarily the vicarious trauma literature (which overlaps with the secondary traumatic stress literature), Kadambi and Ennis (2004) question the empirical support for types of secondary traumatic stress in mental health workers and submit that the prevalence of secondary traumatic stress is overstated. Past secondary traumatic stress research has shown that unresolved, past trauma histories in helpers correlate with secondary traumatic stress. Kadambi and Ennis suggest that existing prevalence of secondary traumatic stress may have to do with findings that therapists working with trauma clients have high rates of past personal abuse histories and client trauma stories may act as triggers for the worker's own trauma disorder. Indeed, Pope and Feldman-Summers's (1992) survey of 153 female and 137 male clinical and counseling psychologists revealed that $69.93 \%$ of the women and $32.85 \%$ of the men reported past histories of either physical or sexual abuse.

In a review of the quality of evidence in 16 vicarious trauma and secondary traumatic stress research articles from 1994-2003, Baird and Kracen (2006) found a variety of findings that are at times contradictory, but also show some differences between vicarious trauma and secondary traumatic stress. Baird and Kracen report persuasive evidence of a link between a personal trauma history and vicarious trauma, but that there is both reasonable evidence for and against a link between personal trauma history and secondary traumatic stress; the amount of exposure to another's trauma material is more indicative of secondary traumatic stress then of vicarious trauma; and perceived coping provides more protection from vicarious trauma then secondary traumatic stress. The results certainly indicate that vicarious trauma and secondary traumatic stress require more research, but within the findings is an indication that the trauma material of others interacts with a helper's past trauma and impaired coping to result in vicarious trauma or secondary traumatic stress.

\subsection{Burnout}

Burnout is a well-developed construct that involves a defense response to occupational stress where there is demanding, psychologically taxing interactions with others in the context of poor social support for coping (Jenkins \& Baird, 2002). Burnout is characterized by emotional exhaustion, disconnection from clients, and poor sense of work accomplishment that is a result of the worker's inability to meet work task demands (Kadambi \& Ennis, 2004). Jenkins and Baird (2002) reported that the Compassion Fatigue Self-Test (which is loaded significantly with trauma symptoms and experiences) had a weak association with the Maslach Burnout Inventory, suggesting that secondary traumatic stress is a different construct than burnout. Vicarious trauma and burnout may have more in common than vicarious trauma has with secondary traumatic stress as studies have found higher correlations between measures of vicarious trauma and measures of burnout than between measures of vicarious trauma and measures of traumatic stress (Kadambi \& Ennis, 2004).

Although burnout theoretically affects mainly an individual's work experience, vicarious trauma and secondary traumatic stress have a wider negative impact on a worker's important areas of functioning (Kadambi \& Ennis, 2004). This argues in favor of secondary traumatic stress and vicarious trauma being a manifestation of PTSD as secondary traumatic stress and vicarious trauma includes symptoms such as disturbing sensory memories, avoidance, intrusive imagery, physiological arousal, functional impairment, lower affect tolerance, and disturbances in beliefs systems (Bride, Jones, \& MacMaster, 2007; Kadambi \& Ennis, 2004). These symptoms can represent the process of normal adaptation to an extreme stressor, maladaptation to a stressor, or if chronic, the emergence of pathology (McFarlane \& Yehuda, 2000). Additionally, secondary traumatic stress experiences by mental health workers results in impairment at work raising ethical questions of competent practice if not treated (Trippany, 2000; Trippany White Kress, \& Wilcoxon, 2004). Impairments can also occur in the worker's private life to include disruption of personal relationships, somatic symptoms, and substance abuse (Miller, 1998). A cluster of symptoms or psychological phenomena is representative of a disorder if it meets the clinically significant standard of causing considerable distress or impairment in important areas of functioning such as occupation or social (Spitzer \& Wakefield, 1999). Clearly, the effect reported in the literature of secondary traumatic stress and vicarious trauma on worker well-being meets the standard of a clinical disorder much the same way PTSD does.

\subsection{Dissociation}

Instead of dissociation as a secondary feature of trauma disorders, van der Hart, Nijenhuis, and Steel (2005) conceptualized dissociation as a central feature of traumatic stress. More specifically, Siegel (1995) hypothesized that trauma disorders involve a dissociation between intact implicit memory and deficient explicit memory leading to avoidance behaviors, hyperarousal, startle response, somatic symptoms, fictional narratives, reenactment, and sudden shifts in behaviors. Grigsby and Stevens (2002) also outlined a number of discrepancies in cognition and behavior due to dissociations in implicit and explicit memory. Research indicates that persons who experience peritraumatic dissociation are statistically more likely to develop trauma symptomatology and long-term psychopathology (Bremner \& Brett, 1997; Brewin, Andrews,\& Valentine, 2000; Griffin, Resick, \& Mechanic, 1997; Ursano et al., 1999). Although 
research by Morgan et al. (2001) suggests that some dissociation under stress is normal and other factors are likely present in individuals who go on to develop trauma disorders.

Other individual traits may predispose persons to dissociation. In researching out-of-body experiences, Gow, Lang, and Chant (2004) found the traits of fantasy proneness and absorption (i.e., hypotonic susceptibility) are highly correlated with non-pathological dissociation, as well as with pathological somatoform dissociation. Absorption in regards to dissociation involves a narrowing of attentional focus that may result in encoding deficits (Halligan, Michael, Clark, \& Ehlers, 2003). van der Hart et al. (2005) postulated that trauma related dissociation differs from alterations in consciousness (e.g., absorption, hypnotizability). However, Bryant, Guthrie, \& Moulds (2001) found that individuals high in hypnotizability (i.e., a stable construct associated with the trait of absorption) display higher levels of dissociation in reaction to trauma.

\subsection{Hypotheses}

Previous research indicates that psychobiological components act as a diathesis for trauma symptoms, including the commonly shared symptoms of dissociation and absorption tendencies, which appear across a spectrum of trauma disorders to include PTSD and secondary traumatic stress (Bremner, 2002; Butler, Duran, Jasiukaitis, Koopman, \& Spiegel, 1996; McFarlane \& Yehuda, 2000; McKeever \& Huff, 2003; McNally, Bryant, \& Ehlers, 2003; van der Kolk, 2001). Past research in secondary traumatic stress and vicarious trauma has already shown the prominent role a mental health worker's past abuse history plays in developing secondary traumatic stress or vicarious trauma. Only a few studies have focused on individual traits such as level of empathy (Abendroth \& Flannery, 2006) and absorption tendencies (Wertz, 2000) in secondary traumatic stress, but none has looked at the role of these traits in burnout. I hypothesize that general dissociation and absorption will positively correlate with secondary traumatic stress and burnout, but not with compassion satisfaction. Although a measure specifically targeting vicarious trauma was not used in this study, it can be assumed that given vicarious trauma's close relationship with burnout, and to some extent secondary traumatic stress, vicarious trauma could be implicated in the results. Since the literature supports the assertion that trauma disorders are the exception and resiliency is the rule (Astur et al., 2006; Foa \& Riggs, 1995; King, King, Fairbank, Keane, \& Adams, 1998; McFarlane \& Yehuda, 2000; McKeever \& Huff, 2003; McNally et al., 2003; Morgan et al., 2001), I hypothesize that more participants will report compassion satisfaction then secondary traumatic stress or burnout.

\section{Method}

\subsection{Participants}

Five of the 11 Maine mental health agencies with contracts to provide crisis services to assigned catchment areas agreed to participate. Mobile crisis workers (MCW) are generally unlicensed, supervised mental health workers who hear multiple stories of past and current trauma experiences and may witness suicides in progress, the bodies of completed suicides, self-mutilation in progress, or injuries sustained from assaults. Inclusion criteria included MCWs who work part-time ( 20 or greater hours a week) or full time ( 40 or greater hours a week). Exclusion criteria included per diem crisis workers who worked fewer than 20 hours a week. The researcher did not gather biographical and demographic information to ensure anonymity. There is empirical support that anonymity (versus confidentiality) increases self-report response rates especially for negative or occupationally sensitive behaviors such as burnout, secondary traumatic stress, and dissociation measured in this study (Levine, Breitkopf, Sierles, \& Camp, 2003; Ong \& Weiss, 2000).

\subsection{Measures}

General dissociation experiences (DES) and dissociation absorption experiences (DESAB) were assessed by the Dissociative Experiences Scale II (DES II; Carlson \& Putnam, 1993). The DES II measures depersonalization, absorption, and memory deficits on a continuum and not the presence of a dissociative state; it is not a diagnostic tool for dissociative disorders (Carlson \& Putnam, 1993; Coe, Dalenberg, Aransky, \& Reto, 1995). Test-retest reliability is .85 and internal consistency reliability is .93 (Waller, 1995). The DES II demonstrated good construct validity (Carlson \& Putnam, 1993), good discrimination validity, and good convergent validity (Frischholz et al., 1991).

Secondary traumatic stress (STS), burnout (BO), and compassion satisfaction (CS) were assessed by the Professional Quality of Life Scale R-IV (ProQOL), which is the third version of the revised Compassion Fatigue Self Test originally published by Charles Figley (Stamm, 2005). The ProQOL contains three 10-item scales that produce scores for STS, BO, and CS; there is no total score (Stamm, 2005). Stamm (2005) reports alpha reliability for the three scales to be CS alpha $=.87, \mathrm{BO}$ alpha $=.72$, and STS alpha $=.80$. The ProQOL demonstrated good construct validity, convergent validity, and discrimination validity (Stamm, 2005). 


\subsection{Procedures}

The Walden University Institutional Review Board approved this study. The researcher sent a large postal envelope to the directors of the five agencies containing individual packets for MCWs. The directors of the crisis units distributed the packets to MCWs who met inclusion criteria. The individual packets contained an informed consent form, DES II, ProQOL, and a self-addressed, stamped envelope to allow participants to return items to researcher without further contact with crisis director. Upon receipt, the researcher assigned a unique, numerical identifier written on the return envelope, consent form, DES II, and ProQOL. Return rate was $45.8 \%$. This study analyzed scores from 30 packets, which met power analysis requirements of 28 needed to maintain power at $80 \%$ for a predicted large effect size $(r=.5)$ at alpha .05 of a one-tailed test (Cohen, 1992; Lenth, 2006). The researcher analyzed the data obtained for this study using SPSS Graduate Pack 13.0 for Windows (SPSS, 2004) software.

\section{Results}

\subsection{Descriptive Summary}

Descriptive statistics supported the resiliency prediction of this study. Stamm (2005) set the normal range CS for scoring purposes at 33-42 with the average score 37 (SD 7). In this study, the mean CS score was 37 (SD 5.9); 63\% of scores were within this range (see Table 1). Combined with scores greater than 42 (high satisfaction), $80 \%$ of scores reflect average to above average CS. Stamm set the normal range STS for scoring purposes at 8-17 with the average score 13 (SD 6). In this study, the mean STS score was 12.7 (SD 6); $50 \%$ of scores were within this range (see Table 1). Combined with scores less than 8 (low stress), $76 \%$ of scores reflect average to below average STS. Stamm set the normal range of BO for scoring purposes at 18-27 with the average score 22 (SD 6). In this study, the mean BO score was 20.12 (SD 5.29); 67\% of scores were within this range (see Table 1). Combined with scores less than 18 (low burnout), $93 \%$ of scores reflect average to below average BO.

Ross, Joshi, and Currie (1990) report a mean total score of 10.8 (SD 10.2) on the DES II in a general population study. According to Carlson and Putnam (1993), total scores of 20 on the DES II require further investigation and scores above 30 indicate severe symptoms. The mean DES II score in this study was 10.11 (SD 6.17; see Table 1). Only 6\% of scores in this study were above 20 and no scores were above 30. Ross, Ellason, \& Anderson (1995) report the mean score of the DESAB subscale is 17.46 (SD 5.25) in the general population and a mean score of 53.82 (SD 5.61) in persons diagnosed with dissociative identity disorder. The mean score in this study was 17.33 (SD 9.77; see Table 1), reflecting scores found in the general population. Only $26 \%$ of scores were above one standard deviation of the mean (i.e., above 22.71) set by Ross et al. (1990) for scores in the general population. No scores were within one standard deviation of the mean for scores by persons diagnosed with dissociative identity disorder (Ross et al., 1995).

\subsection{Correlational Analyses}

As predicted, CS did not correlate significantly with DES $(r=.12)$ or DESAB $(r=.07$; see Table 1$)$. The results support prediction in that as a MCW's STS score increased so did the total level of reported dissociative experiences. A Pearson correlation addressed the relationship between level of STS and level of total DES (see Table 1). The correlation was found to be statistically significant at an alpha level of $.05, \mathrm{r}(28)=.306, \mathrm{p}<.05$ and represents a moderate effect. The $95 \%$ confidence interval for the correlation coefficient was -.06 to .6.

Also, as predicted, as a MCW's STS score increased so did the total level of reported dissociative absorption experiences. A Pearson correlation addressed the relationship between level of STS and level of DESAB (see Table 1). The correlation was found to be statistically significant at an alpha level of $.05, \mathrm{r}(28)=.323, \mathrm{p}<.05$ and represents a moderate effect. The $95 \%$ confidence interval for the correlation coefficient was -.042 to .612 .

Analysis of the BO data supported predictions as well. As a MCW's BO score increased so did the total level of reported dissociative experiences. A Pearson correlation addressed the relationship between level of $\mathrm{BO}$ and level of total DES (see Table 1). The correlation was found to be statistically significant at an alpha level of $.05, \mathrm{r}(28)=.439, \mathrm{p}$ $<.05$ and represents a moderate effect. The 95\% confidence interval for the correlation coefficient was .094 to .69.

Also, as predicted, as a MCW's BO score increased so did the total level of reported dissociative absorption experiences. A Pearson correlation addressed the relationship between level of BO and level of DESAB (see Table 1). The correlation was found to be statistically significant at an alpha level of $.05, \mathrm{r}(28)=.434, \mathrm{p}<.05$ and represents a moderate effect. The $95 \%$ confidence interval for the correlation coefficient was .088 to .686 . 
Table 1 Relationships Between Dissociative Experiences Scale II scores and Professional Quality of Life Scale R-IV scores $(\mathrm{N}=30)$

\begin{tabular}{llccccc}
\hline & Scale & 1 & 2 & 3 & 4 & 5 \\
\hline 1. & DES & - & & & & \\
2. & DESAB & $\mathrm{a}$ & - & & & \\
3. & STS & $.306^{*}$ & $.323^{*}$ & - & - & \\
4. & BO & $.439^{*}$ & $.434^{*}$ & $\mathrm{~b}$ & $\mathrm{~b}$ & - \\
5. & CS & .120 & .066 & $\mathrm{~b}$ & 20.12 & 37.06 \\
& \multicolumn{1}{c}{$M$} & 10.11 & 17.33 & 12.70 & 5.29 & 5.91 \\
& \multicolumn{1}{c}{$S D$} & 6.17 & 9.77 & 6.02 & $7-30$ & $21.00-47.00$ \\
& Range & $.46-26.79$ & $1.00-37.50$ & $4.00-28.00$ & &
\end{tabular}

Note : DES = DES II total score; DESAB = DES II Absorption-Imaginative Involvement subscale; STS = ProQOL Compassion fatigue/Secondary Trauma scale; $\mathrm{BO}=$ ProQOL Burnout scale; $\mathrm{CS}=$ ProQOL Compassion Satisfaction scale.

${ }^{\mathrm{a}}$ Scales within DES II not compared to each other. ${ }^{\mathrm{b}}$ Scales within ProQOL not compared to each other.

$* p<.05$.

\section{Discussion}

The results of this study provide moderate, significant correlational evidence that dissociation proneness in general and the dissociation factor of absorption might be an individual characteristic of MCWs in Maine who experience secondary traumatic stress and burnout. The findings emerge from the context that dissociation experiences, secondary traumatic stress, and burnout in this population were low, whereas compassion satisfaction was the norm. Secondary traumatic stress may well be a result of the individual's own vulnerability and trauma history activated by over absorption into the trauma stories of others, instead of secondary traumatic stress caused primarily by exposure to another's trauma experience or the inevitability of burnout.

This is a preliminary study with a small sample size and therefore includes a number of limitations. As a correlation study, it can only address issues of covariation, but cannot answer questions of directionality or causation. The participants self-selected and do not represent a random sample of the general population or the cohort population. The measures in this study use transparent statements and participants could have made assumptions that biased responses toward well-being or pathology.

The study targeted MCWs who may possess unique characteristics from the general population. These characteristics involve the ability to tolerate interacting with individuals in emotional distress, in emotionally charged environments, in environments of varying degrees of risk, as well as exposure to images of physical trauma. However, the population of MCWs studied is likely to represent a subset of a first responder population and results could be relevant (i.e., generalize) to the first responder population.

The results of this study warrant further research on the role of dissociation tendencies in pathological outcomes for mental health workers. Interestingly, measures of mindfulness, such as the Mindful Attention Awareness Scale, incorporate dissociation and absorption questions similar to items on the DES II such as arriving at a destination without recalling the trip, poor memory of or inattention to conversations, inattention to physical sensations, and engaging in activates without awareness (Brown \& Ryan, 2003; Carlson \& Putnam, 1993). Indeed, mindfulness (awareness of the present moment) might be considered the opposite of dissociation and absorption (lack of awareness of the present moment or mindlessness). Mindfulness is associated with a number of health and wellness outcomes, whereas mindlessness (or mind-wandering) is associated with distress and pathological outcomes (Brown \& Ryan, 2003; Davidson \& McEwen, 2012).

Prior research suggests that mindfulness can increase therapist presence and client treatment outcomes (Grepmair, Mitterlehner, Loew, \& Nickel, 2007) and therefore should be part of counseling training. The results of this study suggest that mental health workers could benefit from training in mindfulness techniques to minimize dissociation and absorption, decrease secondary trauma symptoms (likely best identified as PTSD), and prevent burnout while increasing psychological well-being (Brown \& Ryan, 2003; Davidson \& McEwen, 2012; Hayes, 2004; Linehan, 1993). 


\section{Acknowledgements}

This article is based on research for a graduate thesis conducted by Keith A. Plouffe under the direction of thesis chair Robyn L. Trippany at Walden University. I express my appreciation to the anonymous crisis workers who gave of their time and selves to participate in this study and the directors of crisis services who opened their doors to me.

\section{References}

Abendroth, M., \& Flannery, J. (2006). Predicting the risk of compassion fatigue. Journal of Hospice \& Palliative Nursing, 8(6), 346-356.

Astur, R.S., St. Germain, S. A., Tolin, D., Ford, J., Russel, D., \& Stevens, M. (2006). Hippocampus function predicts severity of post-traumatic stress disorder. CyberPsychology \& Behavior, 9(2), 234-240. http://dx.doi.org/ 10.1089/cpb.2006.9.234

Baird, K., \& Kracen, A. C. (2006). Vicarious traumatization and secondary traumatic stress: A research synthesis. Counseling Psychology Quarterly, 19(2), 181-188. http://dx.doi.org/ 10.1080/09515070600811899

Bremner, J. D. (2002). Does stress damage the brain?: Understanding trauma-related disorders from a mind-body perspective. New York, NY: W. W. Norton \& Co.

Bremner, J. D., \& Brett, E. (1997). Trauma-Related Dissociative States and Long-Term Psychopathology in Posttraumatic Stress Disorder. Journal of Traumatic Stress, 10(1), 37-49. http://dx.doi.org/ 10.1023/A:1024804312978

Brewin, C. R., Andrews, B., \& Valentine, J. D. (2000). Meta-analysis of risk factors for posttraumatic stress disorder in trauma-exposed adults. Journal of Consulting and Clinical Psychology, 68(5), 748-766.

Bride, B. E., Jones, J. L., \& MacMaster, S. A. (2007). Correlates of secondary traumatic stress in child protective services workers. Journal of Evidence-Based Social Work, 4(3/4), 69-80. http://dx.doi.org/10.1300/J394v04n03_05

Brown, K. W., \& Ryan, R. M. (2003). The benefits of being present: Mindfulness and its role in psychological well-being. Journal of Personality and Social Psychology, 84(4), 822-848. http://dx.doi.org/ 10.1037/0022-3514.84.4.822

Bryant, R. A., Guthrie, R. M., Mould, M. L. (2001). Hypnotizability in acute stress disorder. American Journal of Psychiatry, 158(4), 600-604. http://dx.doi.org/ 10.1176/appi.ajp.158.4.600

Butler, L. D., Duran, R. E., Jasiukaitis, P., Koopman, C., \& Spiegel, D. (1996). Hypnotizability and traumatic experience: A diathesis-stress model of dissociative symptomatology. American Journal of Psychiatry, 153(Suppl), $42-63$.

Carlson, E. B., \& Putnam, F. W. (1993). An update on the Dissociative Experiences Scale. Dissociation, 6(1), $16-27$.

Coe, M. T., Dalenberg, C. J., Aransky, K. M., \& Reto, C. S. (1995). Adult attachment style, reported childhood violence history and types of dissociative experiences. Dissociation, 1711(1), 142-154.

Cohen, J. (1992). A Power Primer. Psychological Bulletin, 112(1), 155-159. http://dx.doi.org/ 10.1037/0033-2909.112.1.155

Davidson, R. J., \& McEwen, B. S. (2012). Social influences on neuroplasticity: Stress and interventions to promote well-being. Nature Neuroscience, 15(5), 689-695. http://dx.doi.org/10.1038/nn.3093

Foa, E. B., \& Riggs, D. S. (1995). Posttraumatic stress disorder following assault: Theoretical considerations and empirical findings. Current Directions in Psychological Science, 4(2), 61-65. http://dx.doi.org/ 10.1111/1467-8721.ep10771786

Frischholz, E. J., Braun, B. G., Sachs, R. G., Schwartz, D. R., Lewis, J., Shaeffer, D. M., Westergaard, C., \& Pasquotto, J. N. (1991). Construct validity of the Dissociative Experience Scale (DES): I. The relationship between the DES and other self-report measures of DES. Dissociation, 4(4), 185-188.

Gow, K., Lang, T., \& Chant, D. (2004). Fantasy proneness, paranormal beliefs and personality features in out-of-body experiences. Contemporary Hypnosis, 21(3), 107-125. http://dx.doi.org/ 10.1002/ch.296

Grepmair, L., Mitterlehner, F., Loew, T., \& Nickel, M. (2007). Promotion of mindfulness in psychotherapists in training: Preliminary study. European Psychiatry, 22(8), 485-489. http://dx.doi.org/ 10.1016/j.eurpsy.2007.02.004

Griffin, M. G., Resick, P. A., \& Mechanic, M. B. (1997). Objective assessment of peritraumatic dissociation: Psychophysiological indicators. American Journal of Psychiatry, 154(8), 1081-1088.

Grigsby, J., \& Stevens, D. (2002). Memory, neurodynamics, and human relationships. Psychiatry: Interpersonal and 
Biological Processes, 65(1), 13-34. http://dx.doi.org/ 10.1521/psyc.65.1.13.19762

Halligan, S. L., Michael, T., Clark, D. M., \& Ehlers, A. (2003). Posttraumatic stress disorder following assault: The role of cognitive processing, trauma memory, and appraisals. Journal of Consulting and Clinical Psychology, 71(3), 419-431. http://dx.doi.org/ 10.1037/0022-006X.71.3.419

Hayes, S. C. (2004). Acceptance and commitment therapy, relational frame theory, and the third wave of behavioral and cognitive therapies. Behavior Therapy, 35(4), 639-665. http://dx.doi.org/10.1016/S0005-7894(04)80013-3

Jenkins, S. R., \& Baird, S. (2002). Secondary traumatic stress and vicarious trauma: A validation study. Journal of Traumatic Stress, 15(5), 423-432. http://dx.doi.org/ 10.1023/A:1020193526843

Kadambi, M. A., \& Ennis, L. (2004). Reconsidering vicarious trauma: A review of the literature and it's limitations. Journal of Trauma Practice, 3(2), 1-21. http://dx.doi.org/ 10.1300/J189v03n02_01

King, L. A., King, D. W., Fairbank, J. A. Keane, T. M., \& Adams, G. (1998). Resilience-recovery factors in post-traumatic stress disorder among female and male Vietnam veterans: Hardiness, postwar social support, and additional stressful life events. Journal of Personality and Social Psychology, 74(2), 420-434. http://dx.doi.org/ 10.1037/0022-3514.74.2.420

Lenth, R.V. (2006). Java Applets for Power and Sample Size [Computer software]. Retrieved from http://www.stat.uiowa.edu.

Levine, R. E., Breitkopf, C. R., Sierles, F. S., \& Camp, G. (2003). Complications associated with surveying medical student depression: The importance of anonymity. Academic Psychiatry, 27(1), 12-8.

Linehan, M. (1993). Cognitive-behavioral treatment of borderline personality disorder. New York: Guilford Press.

McFarlane, A. C., \& Yehuda, R. (2000). Clinical treatment of posttraumatic stress disorder: Conceptual challenges raised by recent research. Australian \& New Zealand Journal of Psychiatry, 34(6), 940-953.

McKeever, V. M., \& Huff, M. E. (2003). A Diathesis-stress model of posttraumatic stress disorder: Ecological, biological, and residual stress pathways. Review of General Psychology, 7(3), 237-250. http://dx.doi.org/ 10.1037/1089-2680.7.3.237

McNally, R. J., Bryant, R. A., \& Ehlers, A. (2003). Does early psychological intervention promote recovery from posttraumatic stress? Psychological Science in the Public Interest, 4(2), 45-79.

Miller, L. (1998). Our own medicine: Traumatized psychotherapists and the stresses of doing therapy. Psychotherapy, 35(2), 137-146. http://dx.doi.org/ 10.1037/h0087708

Morgan, C. A., Hazlett, G., Wang, S., Richardson, E. G., Schnurr, P., \& Southwick, S. M. (2001). Symptoms of dissociation in humans experiencing acute, uncontrollable stress: A prospective investigation. American Journal of Psychiatry, 158(8), 1239-1247. http://dx.doi.org/10.1176/appi.ajp.158.8.1239

Ong, A. D., \& Weiss, D. J. (2000). The impact of anonymity on responses to sensitive questions. Journal of Applied Social Psychology, 30(8), 1691-1708. http://dx.doi.org/10.1111/j.1559-1816.2000.tb02462.x

Pope, K. S., \& Feldman-Summers, S. (1992). National survey of psychologists' sexual and physical abuse history and their evaluation of training and competence in these areas. Professional Psychology: Research and Practice, 23(5), 353-361. http://dx.doi.org/ 10.1037/0735-7028.23.5.353

Ross, C. A., Ellason, J. W., \& Anderson, G. (1995). A factor analysis of the Dissociative Experiences Scale (DES) in dissociative identity disorder. Dissociation, 8(4), 229-235.

Ross, C. A., Joshi, S., \& Currie, R. (1990). Dissociative experiences in the general population. The American Journal of Psychiatry, 147(11), 1547-1552.

Siegel, D. J. (1995). Memory, trauma, and psychotherapy: A cognitive science view. Journal of Psychotherapy Practice and Research, 4(2), 93-122.

Spitzer, R. L., \& Wakefield, J. C. (1999). DSM-IV diagnostic criterion for clinical significance: Does it help solve the false positive problem [Electronic version]? American Journal of Psychiatry, 156(12), 1856-1864.

SPSS Inc. (2004). SPSS Graduate Pack (Version 13.0) [Computer software]. Chicago: SPSS Inc.

Stamm, B. H. (2005). The ProQOL Manual. The Professional Quality of Life Scale: Compassion Satisfaction, Burnout, and Compassion Fatigue/Secondary Trauma Scales. Lutherville, MD: Sirdran Press.

Trippany, R. L. (2000). Predictors of vicarious traumatization: Female therapists for adult survivors versus female therapists for child survivors of sexual victimization. Dissertation Abstracts International: Section A. Humanities 
and Social Sciences, 62(3), 926A.

Trippany, R. L., White Kress, V. E., \& Wilcoxon, S. A. (2004). Preventing vicarious trauma: What counselors should know when working with trauma survivors. Journal of Counseling \& Development, 82(1), 31-37.

Ursano, R. J., Fullerton, C. S., Epstein, R. S., Crowley, B., Vance, K., Kao, T. C., \& Baum, A. (1999). Peritraumatic dissociation and posttraumatic stress disorder following motor vehicle accidents. American Journal of Psychiatry, 156(11), 1808-1810.

van der Hart, O., Nijenhuis, E. R., \& Steele, K. (2005). Dissociation: An insufficiently recognized major feature of complex posttraumatic stress disorder. Journal of Traumatic Stress, 18(5), 413-423. http://dx.doi.org/ $10.1002 /$ jts.20049

van der Kolk, B. A. (2001). The psychobiology and psychopharmacology of PTSD. Human Psychopharmacology: Clinical and Experimental, 16(S1), S49-S64. http://dx.doi.org/ 10.1002/ hup.270

Versola-Russo, J. M. (2005). Vicarious victims of trauma: A literature review. Journal of Police Crisis Negotiations, 5(2), 59-80. http://dx.doi.org/ 10.1300/J173v05n02_05

Waller, N. G. (1995). Test review of the Dissociative Experiences Scale. From J. C. Conoley \& J. C. Impara (Eds.), The twelfth mental measurements yearbook [Electronic version].

Wertz, C. A. (2000). Vicarious traumatization: The relationship of absorption, emotional empathy and exposure to traumatized clients to PTSD symptom-like behavior in therapists. Dissertation Abstracts International, 61(9), 5013B. Retrieved June 11, 2008, from ProQuest Digital Dissertations database. (Publication No. AAT 9988060)

\section{(cc) $\mathrm{BY}$}

This work is licensed under a Creative Commons Attribution 3.0 License. 